NIST GCR 15-994

\title{
Community Resilience Workshop: Release of Draft Community Resilience Planning Guide for Public Comment April 27, 2015
}

David R. Mizzen Applied Research Associates, Inc.

This publication is available free of charge from:

http://dx.doi.org/10.6028/NIST.GCR.15-994

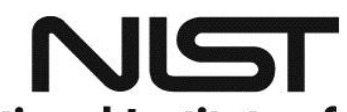


NIST GCR 15-994

\section{Community Resilience Workshop: Release of Draft Community Resilience Planning Guide for Public Comment April 27, 2015}

Prepared for U.S. Department of Commerce Operating Unit National Institute of Standards and Technology Gaithersburg, MD

David R. Mizzen Applied Research Associates, Inc.

This publication is available free of charge from: http://dx.doi.org/10.6028/NIST.GCR.15-994

July 2015

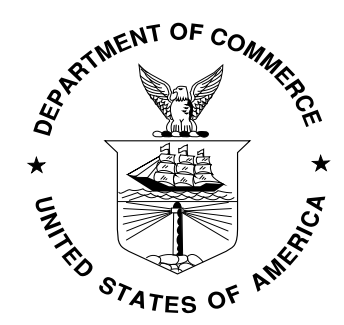

U.S. Department of Commerce Penny Pritzker, Secretary

National Institute of Standards and Technology Willie E. May, Under Secretary of Commerce for Standards and Technology and Director 
This publication was produced as part of contract SB1341-13-CN-0084 with the National Institute of Standards and Technology. The contents of this publication do not necessarily reflect the views or policies of the National Institute of Standards and Technology or the US Government. 


\section{Acknowledgements}

The Community Resilience Workshop, held at Texas Southern University on April 27, 2015, was organized by the National Institute of Standards and Technology (NIST). The workshop served as the release of the Draft Resilience Planning Guide for Public Comment. Both the workshop and this report benefitted from the efforts of many individuals. The author of this document would like to express his gratitude to the following individuals who made significant contributions to the planning, organization, and execution of a successful workshop:

- Tonia Bohnen, Advanced Innovations and Marketing, LLC

- Stephen Cauffman, NIST

- Erica Kuligowski, NIST

- Therese McAllister, NIST

- Nancy McNabb, NIST

The author is also grateful to the writing team and additional NIST staff who participated in the quarterly workshops, assisted in developing the Draft Resilience Planning Guide for Public Comment over the past 18 months, and incorporated stakeholder input into the document:

- Erin Ashley, AECOM

- Don Ballantyne, Ballanytne Consulting, LLC

- David Butry, NIST

- Joseph Englot, HNTB

- Stanley Gilbert, NIST

- Erich Gunther, EnerNex, LLC

- Howard Harary, NIST

- Matthew Heyman, Impressa Management Solutions, LLC

- Frank Lavelle, Applied Research Associates, Inc.

- Stuart McCafferty, GridIntellect, LLC

- Kevin Morley, American Water Works Association

- Robert Pekelnicky, Degenkolb Engineers

- Chris Poland, Consulting Engineer

- Liesel Ritchie, University of Colorado at Boulder

- Adrienne Sheldon, AECOM

- Scott Tezak, TRC Solutions

- Peter Vickery, Applied Research Associates, Inc.

- Jay Wilson, Clackamas County, Oregon

- Kent Yu, SEFT Consulting Group

- Theodore Zoli, HNTB

The workshop also benefitted from an interesting panel session. We wish to thank the following individuals who shared their insightful input with the attendees:

- John 'Rusty' Russell, City of Huntsville, AL

- Anthony Rosano, Howard County, MD Office of Emergency Management

- Greg Guibert, City of Boulder, CO

- Courtney Barker, City of Satellite Beach, FL

Most importantly, the author wishes to thank the participants who attended the workshop and provided input based on their expertise. The workshop would not have been a success without you. We look forward to your continued input at future Disaster Resilience Standards Panels (DRSP) meeting/workshops. 


\section{Community Resilience Workshop: Release of Draft Community Resilience} Planning Guide for Public Comment

Texas Southern University

Houston, TX

April 27, 2015

Meeting Summary

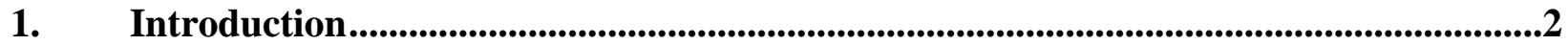

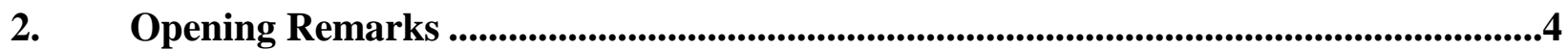

3. NIST Community Resilience Program Overview ...................................................6

4. Introduction to Community Resilience Planning Guide Volume I ...............................8

5. Introduction to Community Resilience Planning Guide Volume II............................15

6. Panel Session: Implementation of Community Resilience Planning Guide ................21

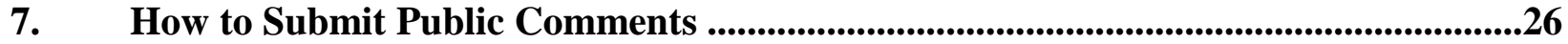




\section{Introduction}

Presidential Policy Directive 8 defines resilience as "the ability to adapt to changing conditions and withstand and rapidly recover from disruptions due to emergencies." Presidential Policy Directive 21 expands the definition to include "the ability to prepare for and adapt to changing conditions and withstand and recover rapidly from disruptions. Resilience includes the ability to withstand and recover from deliberate attacks, accidents, or naturally occurring threats or incidents." Many communities have developed disaster response plans to prepare for disaster events. These disaster response plans will help save lives, protect property, and limit economic damage. However, disaster resilience also includes determining vulnerabilities, improving performance of the built environment during a disaster event, and minimizing recovery times and economic losses.

Buildings and infrastructure systems (transportation, water, wastewater, energy, and communications) play an important role in any community. Historically, buildings and infrastructure systems have been designed and treated as separate entities without much consideration for one another. However, as seen in recent events (e.g., Superstorm Sandy, Hurricane Katrina, and the Joplin Tornado), the dependencies between buildings and infrastructure systems play a huge role in a community's ability to recover in both the short- and long-term.

To address this problem, NIST has led a team over the past 18 months that has convened quarterly workshops in different regions of the country to inform development of a comprehensive, communitybased community resilience planning guide. The goal of previous workshops has been to engage a diverse group of stakeholders and obtain their input for developing this guide. Version 1.0 of the Community Resilience Planning Guide for Buildings and Infrastructure Systems (Guide) provides regional, state, local, and tribal authorities with a methodology that can be used to plan for and support community resilience. NIST plans to convene a Disaster Resilience Standards Panel (DRSP) in 2015 to expand on and refine Version 1.0 of the Guide. The DRSP will also develop a Community Resilience Implementation Guideline.

NIST held the first stakeholder workshop at the NIST Gaithersburg, MD Campus to kick-off Guide development. NIST held the second workshop at the Stevens Institute of Technology in Hoboken, NJ on July 30, 2014. The third workshop was held at the NCED Conference Center and Hotel in Norman, OK on October 27-28, 2014, and the fourth workshop was held at the Hilton San Diego/Del Mar on February 18-19, 2015. The fifth workshop, summarized in this document, was at Texas Southern University in Houston, TX. Between the fourth and fifth workshops, the writing team developed the $100 \%$ draft of the Community Resilience Planning Guide for Buildings and Infrastructure Systems for public comment, incorporating stakeholder input from previous workshops. The Guide consists of two volumes. Volume Icontains a description of a methodology that can be used by communities to plan for resilience, and includes a detailed example to illustrate how this methodology can be used. Volume II contains supporting information related to the social dimensions of a community, dependencies between buildings and infrastructure systems, and detailed information regarding codes, standards, and resilience solutions that can be used to make buildings and infrastructure systems more resilient. The Houston, TX workshop served as the release of the Community Resilience Planning Guide for Buildings and Infrastructure Systems. The draft of the Guide was posted to the NIST website for public review and comments on the day of the workshop.

Figure 1 shows the agenda for the April 27 $7^{\text {th }}$ NIST Community Resilience Workshop held at Texas Southern University in Houston, TX. This document summarizes content from the April $27^{\text {th }}$ workshop. 


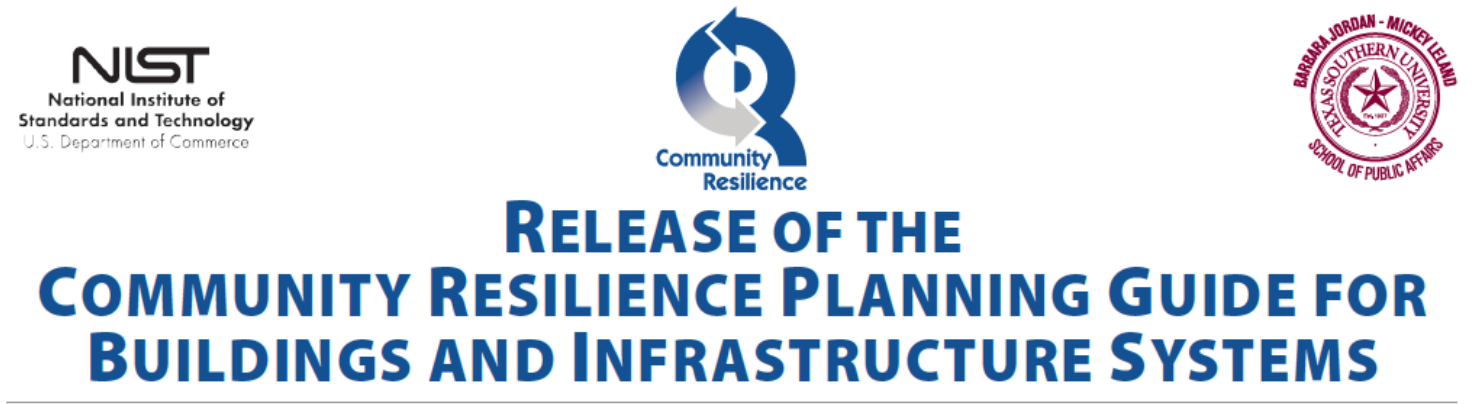

TEXAS SOUTHERN UNIVERSITY • HOUSTON, TEXAS • 4.27.15 AGENDA

\begin{tabular}{|c|c|}
\hline $7: 30 \mathrm{am}-8: 30 \mathrm{am}$ & Check-in and Breakfast \\
\hline \multirow[t]{2}{*}{$8: 30 \mathrm{am}-8: 45 \mathrm{am}$} & $\begin{array}{l}\text { Welcome and Opening Remarks } \\
\text { Dr. Robert Bullard } \\
\text { Dean, Barbara Jordan-Mickey Leland School of Public Affairs, Texas Southern University }\end{array}$ \\
\hline & $\begin{array}{l}\text { Introduction by Dr. Earthea Nance } \\
\text { Associate Dean and Associate Professor Dept. of Urban Planning \& Environmental Policy } \\
\text { Barbara Jordan-Mickey Leland School of Public Affairs }\end{array}$ \\
\hline \multirow[t]{2}{*}{$8: 45 \mathrm{am}-9: 00 \mathrm{am}$} & $\begin{array}{l}\text { Opening Remarks } \\
\text { Dr. Willie May } \\
\text { Acting Under Secretary of Commerce for Standards and Technology, } \\
\text { Acting Director of the National Institute of Standards and Technology }\end{array}$ \\
\hline & $\begin{array}{l}\text { Introduction by Dr. Howard Harary } \\
\text { Director, Engineering Laboratory, National Institute of Standards and Technology }\end{array}$ \\
\hline 9:00 am-9:15 am & $\begin{array}{l}\text { NIST Community Resilience Program Overview } \\
\text { Stephen Cauffman } \\
\text { Manager, NIST Community Resilience Program }\end{array}$ \\
\hline 9:15 am-10:30 am & $\begin{array}{l}\text { Introduction to Community Resilience Planning Guide Volume } 1 \\
\text { (Presentation and participant questions) }\end{array}$ \\
\hline $10: 30 \mathrm{am}-10: 45 \mathrm{am}$ & Break \\
\hline $10: 45 \mathrm{am}-12: 00 \mathrm{pm}$ & $\begin{array}{l}\text { Introduction to Community Resilience Planning Guide Volume } 2 \\
\text { (Presentation and participant questions) }\end{array}$ \\
\hline $12: 00 \mathrm{pm}-1: 00 \mathrm{pm}$ & Lunch \\
\hline $1: 00 \mathrm{pm}-2: 30 \mathrm{pm}$ & $\begin{array}{l}\text { Panel Discussion: } \\
\text { Implementation of Community Resilience Planning Guide } \\
\text { Panelists: } \\
\text { John'Rusty' Russell, Emergency Management Agency Director, Huntsville AL } \\
\text { Anthony Rosano, Resiliency Coordinator, Howard County Office of Emergency Management } \\
\text { Greg Guibert, Chief Resilience Officer, Boulder, CO } \\
\text { Courtney Barker, City Manager, Satellite Beach, FL }\end{array}$ \\
\hline $2: 30 \mathrm{pm}-2: 45 \mathrm{pm}$ & Break \\
\hline $2: 45 \mathrm{pm}-3: 45 \mathrm{pm}$ & $\begin{array}{l}\text { Moderated discussion with all participants on opportunities } \\
\text { and challenges of implementing the Guide }\end{array}$ \\
\hline $3: 45 \mathrm{pm}-4: 00 \mathrm{pm}$ & How to Submit Public Comments \\
\hline $4: 00 \mathrm{pm}$ & Adjourn \\
\hline
\end{tabular}

Figure 1. Agenda for April $27^{\text {th }}$ NIST Community Resilience Workshop 


\section{Opening Remarks}

The Opening Session for the Fifth Stakeholder Workshop of the NIST Community Resilience Program began at 8:30 a.m. Mr. Stephen Cauffman (NIST) delivered introductory remarks and welcomed participants. Dr. Robert Bullard, Dean of the Barbara Jordan-Mickey Leland School of Public Affairs at Texas Southern University, was then introduced to make opening remarks.

\section{Summary of Dr. Bullard's Remarks}

The issues that we face when it comes to natural and human-caused hazards today are tremendous. It is important when speaking about resilience of buildings and infrastructure systems that we talk about the social aspects and vulnerability of a community. In the Gulf Coast, we have experienced and are concerned about events such as Hurricanes Katrina and Ike. We know the impacts that such an event can have on communities and understand the importance of a guidance document that can help us to make our communities more resilient. The whole nation could benefit from guidance to make their buildings and infrastructure systems more resilient.

Dr. Howard Harary, NIST Director of the Engineering Laboratory, then introduced Dr. Willie May, Acting Director of the National Institute of Standards and Technology.

\section{Summary of Dr. May's Remarks}

Today marks the fourth anniversary of the Alabama tornadoes. Nearly every disaster, including Hurricane Ike which impacted this campus, reminds us of the vulnerabilities of buildings and infrastructure systems of communities. We know that every community is different physically and socially, which impacts its ability to respond to and recover from hazard events.

We also know that communities can minimize the physical, economic, and social harm that hazard events can inflict. That is why NIST has undertaken the challenge of developing a Community Resilience Planning Guide for Buildings and Infrastructure Systems. The Guide is intended as a tool that can be used by communities to improve the resilience of their buildings and infrastructure systems. Since every community is different in terms of the hazards they face, their resources, and their social aspects, the implementation of this tool is flexible enough that communities can use it in many ways.

This tool does not stand apart from the work being completed under the National Preparedness Goal issued by the Department of Homeland Security. FEMA reports that more than 24,000 US communities issue mitigation plans, which can help to reduce the amount of damage that occurs when a hazard event does occur. Resilience efforts can further the overall goal of reducing damage after disaster events.

The Guide considers recovery in terms of functionality (e.g., a building needs power and water to function properly). It may be customized by communities as appropriate to account for their size, available resources, social institutions, and other community-specific factors. Planning should be completed ahead of a hazard event, not after. Unfortunately, it is common that planning takes place while communities are recovering from a disaster event. Some communities build back to a higher standard, but many do not. Cedar Rapids (Iowa), as discussed in the Guide, is a good example of a community that took action to incorporate resilience planning into their recovery after the flooding experienced in 2008. Resilience planning and implementation should be done proactively in anticipation of the next hazard event, particularly since we live in one of the most disaster-prone regions in the world. Additionally, changing climate may also add to this problem moving forward. Therefore, improving resilience should be a high priority for communities and the nation to minimize loss and hardship.

Resilient communities are often more likely to attract businesses and, thus, support growth because businesses and insurance companies are becoming more sensitive to increased costs associated with risks 
Community Resilience Workshop: Release of Draft Community Resilience Planning Guide for Public Comment Opening Remarks

from disasters. NIST and our partners have worked to develop this Guide that is the first of its kind. This draft has a lot of useful information. However, this Guide is a living document and will continue to be improved with your input. It will be updated periodically and NIST intends to initiate a panel that will continue to advance the Guide. 


\section{NIST Community Resilience Program Overview}

Before introducing the Guide, Mr. Cauffman provided an overview of the NIST Community Resilience Program to provide background on the program and other activities that will include stakeholder input and participation.

\section{Summary of Mr. Cauffman's Remarks}

[The slides associated with the following text are located on the NIST.gov website.]

Currently, our country is impacted by many types of disasters, which results in billions of dollars of damage annually. Our current approach of rebuilding after a disaster occurs is impractical and inefficient for dealing with natural disasters, particularly in the long-term. Currently, our planning does not account for the interconnected nature of buildings and infrastructure systems, or how their performance impacts the social institutions in a community. Furthermore, the changing nature of hazards is not always considered in planning.

NIST has organized this program into three phases. The first phase (current phase) is the Stakeholder Engagement Phase. This phase includes the development of the Community Resilience Planning Guide and the formation of the Disaster Resilience Standards Panel, which will begin later in 2015 and lead the development of the Community Resilience Implementation Guideline. The second phase (Research Phase), which is being completed in parallel, includes research to develop tools that can support communities in resilience planning. The two main deliverables of the second phase are a Community Resilience Assessment Tool and an Economics-Based Design Support Tool. The NIST Disaster Resilience Fellows have provided significant contributions to the first phase and will be involved in the second phase as well. The third phase includes the Center of Excellence, which was awarded at the previous workshop. The Center of Excellence will develop integrated, multi-scale modeling, develop database architectures, and conduct pilot studies to validate models and database architectures.

Resilience has been defined in a couple of ways by the Federal Government. It was first defined in Presidential Policy Directive-8 (PPD-8) as "the ability to adapt to changing conditions and withstand and rapidly recover from disruption to emergencies." It was later expanded by PPD-2 1 to include "the ability to prepare for and adapt to changing conditions and to withstand and recover rapidly from disruptions. Resilience includes the ability to withstand and recover deliberate attacks, accidents, or naturally occurring threats or incidents." When referring to community resilience, we are not only talking about mitigating risk. We are talking about ensuring that communities can recover to normal function within a reasonable timeframe.

For the purposes of this Guide, "community" refers to a place that is designated by geographical boundaries and functions under the jurisdiction of a governance structure (e.g., city, town, county). Communities have their own identity, history, leadership, and resources. However, some infrastructure systems, such as electric power systems, extend beyond the boundaries of an individual community.

The desired performance of buildings and infrastructure systems are driven by the needs of the social institutions within a community. The built environment can be damaged by both natural and humancaused hazards, and can be influenced by degradation of existing infrastructure and the effects of climate change. To protect against these hazards, we can set performance goals and use a combination of mitigation, response, and recovery to achieve these goals. Overall, this allows communities to achieve the goal of limited disruption for a design-level event and minimize detrimental effects.

The Guide has been developed over the past 18 months, and informed by quarterly workshops over the past year in various regions of the country. The process of collecting stakeholder input began in April last year at the NIST Gaithersburg, MD campus. We then posted a 25\% draft in July 2014 and collected input in our workshop in Hoboken, NJ. Using the feedback we received, we developed a $50 \%$ draft for the Norman, OK workshop in October 2014. This process was used again in preparing the 75\% draft for the San Diego, CA workshop in February 2015, which has led us to the release of the $100 \%$ draft of the 
Guide today. There will be a 60-day public comment period, after which we will address the comments and intend to release a final version in September 2015.

The Guide is targeted to local government, which is envisioned as a logical convener to bring their own stakeholders together to develop plans for resilience. The Guide complements the National Preparedness System and has benefited from contributions from a large team as well as extensive public and private sector input.

Although this is a great first step, this is not a stopping point. Our next step is to form the Disaster Resilience Standards Panel (DRSP), which will have its first meeting later in 2015. It is envisioned that the DRSP will take an active role in developing the Community Resilience Implementation Guidelines that will provide guidance based on existing codes, standards, and best practices. We also intend to support the implementation of the Guide by working with communities that are interested in using it to develop resilience plans, and gaining feedback to support revisions as necessary.

The development of the Guide has benefitted greatly from contributions from the NIST Disaster Resilience Fellows, including Donald Ballantyne and Kevin Morley (Water Infrastructure), Joseph Englot and Ted Zoli (Transportation Infrastructure), Erich Gunther and Stuart McCafferty (Electrical Power Infrastructure), Chris Poland (Community Resilience), Liesel Ritchie (Sociology of Disasters), and Jay Wilson (Emergency Planning and Response). We have also recently added a Business Continuity Fellow (George Huff).

Improving resilience does not have to be prohibitively expensive. Many measures to improve resilience can be implemented over many years. The Guide is intended to be used and customized by communities to set and achieve their own goals for their buildings and infrastructure systems. It promotes planning that takes into account dependencies between buildings and infrastructure systems. The Guide can also be used to help communities prioritize investments to improve resilience.

If you wish to contact me, you can do so via email (stephan.cauffman@ nist.gov or resilience@nist.gov) or phone (301-975-6051). Our website will also be updated regularly and is the source of a lot of useful information for this program (http://www.nist.gov/el/building_materials/resilience/). 
Community Resilience Workshop: Release of Draft Community Resilience Planning Guide for Public Comment Introduction to Community Resilience Planning Guide Volume I

\section{Introduction to Community Resilience Planning Guide Volume I}

After the overview of the NIST Community Resilience Program was completed, Volume I of the planning guide was introduced by the following presenters:

- Dr. Therese McAllister, NIST - Chapters 1-3: Introduction, Form a Collaborative Planning Team, and Understand the Situation

- Mr. Chris Poland, Consulting Engineer - Chapter 4: Determine Goals and Objectives

- Dr. Therese McAllister, NIST - Chapters 5-7: Develop Plan, Approve and Implement Plan, and Future Directions

- Dr. Erica Kuligowski, NIST, and Mr. David Mizzen, Applied Research Associates - Appendix: Community Resilience Planning Example - Riverbend, USA.

Summary of Dr. McAllister's Remarks

[The slides associated with the following text are located on the NIST.gov website.]

Chapter 1 of the Community Resilience Planning Guide for Buildings and Infrastructure Systems provides an overview of the Guide's purpose. The Guide can be used to help communities determine their own long-term resilience goals, develop short- and long-term plans to achieve resilience, prioritize implementation of improvements to the built environment, and address dependencies between infrastructure systems and cascading effects.

Flora et al. introduced this concept [slide 3] of community capitals in 2008. The types of capital are financial capital, built capital, political capital, social capital, human capital, cultural capital, and natural capital. These are all important to communities and impact the recovery of a community after a disaster event.

Resilience can be expressed in terms of the time it takes to recover system functionality following a disruptive event. As can be seen from the chart [slide 4], making modifications to buildings and infrastructure before an event occurs can limit the loss of functionality when an event does occur and shorten the recovery time. Moreover, after an event occurs, we can build back to a higher standard so as to prepare for the next disruptive event and limit recovery time in the future.

There are several other Federal Government activities when it comes to resilience. Our Guide fits in well with these other initiatives. The National Preparedness Goal (NPG) identifies core capabilities intended to strengthen the security and resilience of the US. The National Planning Frameworks, which support the NPG, include frameworks for prevention, protection, mitigation, response, and recovery. By combining all of these, you can achieve resilience, which is the focus of our Guide at the community level. Our Guide is now part of the National Preparedness System, which includes all of the documents that support the NPG.

The National Infrastructure Protection Plan (NIPP) lists 16 critical sectors that focus on services at the national level. Our Guide focuses on the buildings and infrastructure systems (communication, energy, transportation, and water and wastewater) that support these 16 sectors. The Federal Emergency Management Agency (FEMA) Disaster Mitigation Assessment provides guidance for mitigation plans at the county or community level. The Threat and Hazard Identification and Risk Assessment (THIRA) can be used by communities to map their risks to the core capabilities of the NPG.

There are also a number of other (non-Federal) resilience activities, including the SPUR Framework, Oregon Resilience Plan, National Oceanic and Atmospheric Administration's (NOAA's) Coastal Resilience Index, Baseline Resilience Indicators for Communities (BRIC) Community and Regional Resilience Institute's (CARRI) Community Resilience System, Communities Advancing Resilience Toolkit (CART), United Nations International Strategy for Disaster Reduction (UNISDR) Scorecard, and Rockefeller Foundation's 100 Resilient Cities Initiative.

Although we address a lot of issues in the Guide, there are a number of aspects of community resilience 
Community Resilience Workshop: Release of Draft Community Resilience Planning Guide for Public Comment Introduction to Community Resilience Planning Guide Volume I

that are outside of the scope of the effort, such as roles and responsibilities of public-private agencies, social, political and economic strategies or processes, methods of obtaining financial resources and evaluating investment options, natural resources, and the environment.

Our Guide contains a six-step methodology: 1) Form a collaborative planning team; 2) Understand the situation; 3) Determine goals and objectives; 4) Plan development; 5) Plan preparation, review, and approval; and 6) Plan implementation and maintenance.

Chapter 2 of the Guide focuses on Step 1 of the methodology: Form a collaborative planning team. A lot of different stakeholders should be included on the planning team, including elected officials, local government staff, community members, community organizations, and members of the private sector (e.g., banking, health care, etc.). Once the team is formed, a community can work through the second step of the methodology (Chapter 3 of the Guide), which is to understand the situation.

To understand the situation of a given community, it is important to characterize both the social dimensions and built environment of a community and how they interact with one another. Starting with the social dimensions of a community, it is important to understand who the community members are, what social institutions exist in the community as well as their functions, and dependencies between social institutions. It is also important to consider ways that these aspects can be measured and monitored. Maslow's hierarchy can be used as shown on this slide [slide 12] to help define the short-term essentials of a community and the long-term goals of a community for growth and achievement. There are many social institutions that help communities meet these needs, such as family and kinship, government, education, religious, economic, health, community service organizations, and media. These are examples of social institutions that may exist, and will vary from one community to another.

When characterizing the built environment, communities should consider building clusters (sets of buildings that serve a common function) and infrastructure systems that support the social institutions (transportation, energy, communication, and water and wastewater). Communities should also consider and address four types of dependencies: internal (within an infrastructure system), external (interactions with other infrastructure systems), how dependencies change over time in the recovery process, and space (i.e., geography).

Once both the social and built communities have been characterized, communities can link them to one another so that improvements in the performance of the built environment support the social institutions of the community. In the long-term planning process, it is important to consider how the built environment supports the social institutions, particularly the most essential needs. Some social institutions rely on the built environment more than others, and the functions of some parts of the built environment can change. For example, schools can serve as shelters after an event where housing is lost. It is important to know in the planning process if that is an acceptable outcome and what needs to be done to support this change in function.

Summary of Mr. Poland's Remarks

[The slides associated with the following text are located on the NIST.gov website.]

Chapter 4 of the Guide focuses on determining the goals and objectives of the community (Step 3 of the methodology). There are five things that should be done to complete this step. Communities can establish high-level long-term goals, specific desired performance goals of the built environment, define hazards types and levels potentially faced by the community, determine the anticipated performance of the existing built environment, and summarize the results.

Establishing the long-term goals for the community sets the tone for what you are trying to accomplish. Each community will have different long-term goals, such as improving the reliability of infrastructure systems (e.g., electric power), enhancing community functions, reducing commute time for residents and businesses, and revitalizing or repurposing parts of the community that need to be improved. To establish 
Community Resilience Workshop: Release of Draft Community Resilience Planning Guide for Public Comment Introduction to Community Resilience Planning Guide Volume I

the desired performance goals for the built environment, the Guide defines goals in terms of time needed to recover functionality. These performance goals can be used to help prioritize repair and rebuilding efforts. It is important to set the performance goals based on the needs of the social institutions, local economy, and their dependencies. In some cases, it may also be necessary to consider the role of an individual facility or system outside of the community so that it does not disrupt the supply chain or remove your community from the supply chain. Finally, these performance goals will help suggest criteria for new construction as well as retrofits of existing construction.

The National Disaster Recovery Framework developed by FEMA categorized recovery of the built environment into three phases: short (days), intermediate (weeks), and long-term (months). Communities can use these phases to help plan which building clusters and infrastructure systems need to be restored to functionality in each timeframe. To do this, communities can map the needs of the social institutions from Maslow's Hierarchy into the three phases and determine which building clusters and related infrastructure supports these needs. For example, critical facilities, emergency housing, and related infrastructure systems are needed in the short-term; housing, healthcare, school, churches, and related infrastructure are needed in the intermediate term; and commercial and industrial businesses are needed in the long-term recovery of a community.

In terms of the performance levels of individual buildings, we refer to four categories: A) Operational (available in short-term); B) Usable during repair (available in short- to intermediate-term); C) Not Usable (available in intermediate- to long-term); and D) Collapse, which we want to mitigate. To go beyond just the performance of buildings in a hazard event, communities can think about the level of functionality during the recovery process after a hazard event and set their own performance goals based on the desired level of functionality to support their social institutions. In the Guide, we define three levels of functionality for the performance goals: $30 \%$ ) Minimum number needed to initiate activities assigned to the cluster; $60 \%$ ) Minimum number needed to initiate usual operations; $90 \%$ ) Minimum number needed to declare cluster is operating at normal capacity. This idea of building clusters and recovery times is being used in San Francisco as a part of their soft-story initiative to retrofit buildings so that people can shelter-in-place when an earthquake does occur.

Once a community has defined its performance goals based on its social institutions, it can determine its prevalent hazards (e.g., wind, seismic, flood) for three hazard levels (routine, expected, extreme). In the Guide, we define the routine event as one that is expected to occur frequently. The expected event is the design-level event used for buildings, and the extreme event is the maximum considered possible by the community. When anticipating the recovery time needed for buildings and infrastructure systems, it is important to also understand the affected area (local, community, or regional) of a given hazard event as well as the disruption level to the community (minor, moderate, or severe). We have shown examples of past events and their impacts on communities [slide 11]. When estimating the anticipated performance of the built environment, recovery of communities depend on a number of factors, including the level of damage, availability of materials, equipment, and labor as well as dependencies on other infrastructure systems.

At the end of the process of setting performance goals for the buildings and infrastructure systems, they can be summarized into a matrix to understand the goals and anticipated performance for the community as a whole. This first table [slide 13] is for a routine event with a localized affected area and minor disruption. The high level goal here is that there should not be much long-term loss of functionality as is shown by the performance goals ( $90 \%$ boxes) in the tables. The Xs indicate the anticipated performance is not far off of these goals, but there is a need to make improvements to meet the goals.

The next table [slide 14] is for an expected event that affects a community, causing a moderate disruption. You can see that the buildings have a large gap between the goals and the anticipated performance in this example because the buildings are built for life safety, not functionality. The last example performance goals table [slide 15] is the extreme hazard event. These are events that are greater than what we would 
Community Resilience Workshop: Release of Draft Community Resilience Planning Guide for Public Comment Introduction to Community Resilience Planning Guide Volume I

expect and we do not design for them. However, communities can think about theses events in the planning process so that they have strategies in place to recovery functionality of their buildings and infrastructure systems.

Summary of Dr. McAllister's Remarks

[The slides associated with the following text are located on the NIST.gov website.]

Chapter 5 of the Guide (Step 4 of the methodology) discussed the development of a plan for resilience. After completing the performance goals tables, including the summary matrices, communities can evaluate where gaps exist between the desired and anticipated performance. Then, communities can work to identify administrative and construction solutions to close the resilience gaps. Once potential solutions have been identified, they can be prioritized by the planning team and they can develop both short- and long-term implementation strategies.

As previously discussed, resilience gaps can be identified using the performance goals tables [see slide 3], and used to prioritize long-term planning goals based on the social needs of the community. When identifying solutions, the planning team can use the overall community goals to help determine what types of solutions can be used. Public safety is always a concern, but the way in which communities address potential hazard threats can vary. Levees can be used to redirect threats from flooding, and structures can be hardened to reduce damage, which can enable rapid recovery after a hazard event.

When considering solutions, communities can look at staging, combinations of temporary and permanent solutions, and administrative and construction solutions. Examples of administrative solutions include establishing a resilience office with designated leadership, developing and implementing sound land use policies, integrating resilience plans with other community plans, collaborating with nearby communities, and implementing education and awareness programs. Examples of solutions for existing construction include sediment and erosion control, retrofitting public buildings and infrastructure systems, and implementing mandatory retrofitting programs. Solutions for new construction can include adopting and enforcing the latest model building codes/standards for the built environment, enhancing minimum requirements to support resilience goals, and ensuring codes/standards are enforced.

Once all of the potential solutions have been identified, the next step is to prioritize the solutions and develop an implementation strategy. To develop an implementation strategy, solutions can be selected, prioritized, and combined to address resilience gaps. The planning team can also complete cost-benefit analysis for the short- and long-term to understand how the solutions will impact public safety, social needs, and the local economy.

Chapter 6 of the Guide discussed Steps 5 and 6 of the methodology. Step 5 is to document the proposed plan for implementation of the strategy and supporting documentation. The plan should then be shared with stakeholders in the community for public comment, and changes should be made based on those comments, if appropriate. Step 6 of the Guide is to implement the plan as approved and review it periodically to modify/update as necessary. This is an important step to take because becoming more resilient is an ongoing process.

Chapter 7 of the Guide discusses future directions of the NIST Community Resilience Program. NIST encourages stakeholders to provide comments and feedback on the document so that we can understand what you find most useful as well as areas where you feel it can be strengthened. As previously discussed, a Disaster Resilience Standards Panel (DRSP) will be formed later this year. It is intended to be an independent organization that includes a broad spectrum of stakeholders. It is envisioned that the DRSP will support continued development of the Guide and development of Implementation Guidelines as well as identify and promote improved codes, standards, best practices, and tools. The first meeting of the DRSP is anticipated to take place later this year in the DC area. 
Community Resilience Workshop: Release of Draft Community Resilience Planning Guide for Public Comment Introduction to Community Resilience Planning Guide Volume I

Summary of Dr. Kuligowski and Mr. Mizzen's Remarks

[The slides associated with the following text are located on the NIST.gov website.]

The goal of the appendix is to provide an example of a fictional city (Riverbend, USA) that works through the six planning steps of the Guide.

Riverbend, USA is a small city of approximately 50,000 people, situated along the Central River. Like any other city, it has its own unique history, experiences, social needs, economic drivers, and, thus, plan to achieve resilience. In the case of Riverbend, the plan began with a champion of resilience, Ms. Smith, who recently moved to the city after experiencing a disaster event in her former city.

Ms. Smith gained support from the Mayor, City Council, and community to initiate the process of planning for resilience following the steps in the Guide. The first step, corresponding to Chapter 2 of the Guide, was to form a collaborative planning team. As seen in the chart [slide 4], the planning team is overseen by the Riverbend City Council. The planning team oversees seven task groups: hazards, social dimensions, buildings, transportation, energy, communications, and water and wastewater. The hazards task group was responsible for identifying potential hazards. The social dimensions task group defined the social needs and priorities of the community that are the basis for the performance goals discussed in the Guide. The task groups for the buildings and infrastructure systems (transportation, energy, communications, and water and wastewater) identified and characterized their portions of the built environment in the recovery phases for the four building clusters (critical facilities, emergency housing, housing/neighborhoods, and community recovery) listed in the Guide.

Examples of the planning team and task groups are shown on the slides [slides 5-6]. The planning team includes the city manager, city engineer, city planner, and other city staff in addition to representatives from the financial sector, public outreach and information specialists, and representatives from each of the seven task groups. Including representatives from each of the task groups was important so that dependencies between systems could be addressed. The social dimensions task group is quite large and diverse because it incorporates stakeholders from eight institutions (family and kinship, education, economic, government, CSOs, religious/cultural, health, and media).

Step 2 of the planning process (Chapter 3 of the Guide) is to understand the situation, which includes both the social dimensions and the built environment. The social dimensions task group characterized Riverbend's economy as having one major employer called the National Aircraft Parts factory that supplies aircraft parts regionally as well as being the only supplier of parts critical to the armed forces. However, the economy also has a large number of small businesses. The social dimensions task group also collected information on the demographics of Riverbend, including median income, age, education, unemployment rate, emigration, population growth, and other factors that impact the needs of the community. They also collected information on the functions that support the social institutions in the city, such as police and fire departments, health system, education, etc.

In Chapter 9 of Volume II, we provide an example template for a table that can be used to identify dependencies between social institutions [slide 8]. For example, people in Riverbend rely on government and businesses for employment.

As previously discussed, Step 2 of the process also involves characterizing the built environment. The task groups for buildings and infrastructure systems did this in parallel with one another and the social dimensions task group. The buildings task group found that there was a wide array of construction and a significant number of unreinforced masonry buildings in the downtown area. The transportation system consisted mainly of local roads. There was a regional airport approximately 30 miles away from Riverbend, but it had limited commercial service and was not extensively used by Riverbend residents and businesses. The main concern was an Interstate bridge that carried traffic between Riverbend and its neighboring city, Fallsborough. It was the only crossing over the Central River for 10 miles and carried the only water main from the Fallsborough Water Treatment Plant into Riverbend. The city also relied on county services to treat sanitary sewage and storm water. 
Riverbend Gas and Electric provides power and natural gas, while liquid fuel is transported to the city. Communications services (landline, cellular, cable, and Internet) are provided to Riverbend by one national and one regional company. These companies share infrastructure and have the ability to work together when needed.

Once the social and built environments were characterized by the task groups, the planning team worked with the task groups to link them to one another. To do this, the planning team used template tables provided in Chapter 9 of Volume II [see slide 11] to link the social institutions to buildings and each of the infrastructure systems [see slide 12 for example]. These tables allowed the planning team to document: 1) How infrastructure systems and buildings support social institutions; 2) What components of the infrastructure system are essential to supporting the social institutions; 3 ) Potential direct impacts to the community if infrastructure is damaged; and 4) Potential indirect impacts to the community if infrastructure is damaged. Before moving on to Step 3 of the process, Riverbend identified their building clusters based on the links between the social and built environments. As previously discussed, the planning team identified four building clusters for Riverbend's buildings and supporting infrastructure systems: Critical Facilities; Emergency Housing; Housing/Neighborhoods/Business; and Community Recovery [slide 13]. The National Aircraft Parts factory was included in the critical facilities building cluster because it was the largest in Riverbend and it is the sole supplier of critical parts to the armed forces.

Step 3 of the process (Chapter 4 of the Guide) was to determine goals for the community. First, it was important to identify and agree on the high-level, long-term goals for Riverbend. The planning team and task groups agreed that their three high-level goals were to: 1) Minimize disruptions to daily life and commerce; 2) Stabilize employment and attract new business to support economic growth; and 3) Strengthen the ability of government and critical facilities to function after hazard events.

High-level goals for recovery of functionality were then set for each level of hazard event (routine, expected, extreme). For example, the goal of Riverbend's planning team after an expected event was to meet its social needs in 1-12 weeks (i.e., intermediate term) and complete reconstruction projects within two years of the event. The task groups could then fill out the performance goals tables. These tables were completed for buildings and each of the infrastructure systems for the routine, expected, and extreme hazard. As an example, the transportation task group started with the empty performance goals table from Chapter 12 of Volume II in the Guide [slide 16] and customized it to fill it out so that it applied to Riverbend [slide 17]. For the four-lane bridge previously discussed, the task group felt that the bridge needed to perform well in an expected event (regardless of hazard type) and would need to be inspected for safety before re-opening one lane in each direction on the first day for emergency vehicles. The bridge would only have two lanes available on the first day so that more detailed inspections could be completed before re-opening the bridge to all lanes of traffic the day following the hazard event.

Once the performance goals were set, the anticipated performance of the buildings and infrastructure systems could be determined for the hazard types and levels faced by Riverbend. The hazard task group identified earthquake and flooding based on hazard risk maps and historical data of past events that occurred in Riverbend. This performance goal table [slide 19] is for the expected earthquake with an affected area of the community and a moderate disruption level. Again, using the transportation infrastructure system as an example, the anticipated performance was determined by the task groups and indicated in the performance goals tables with an $X$ [slide 19]. As can be seen, the transportation infrastructure was anticipated to perform close to the desired performance goals. The task group determined that there may be some cracking and damage to roads, but they would be fully operational within two weeks. The bridge between Riverbend and Fallsborough would suffer some damage, but would be repaired within one month.

After the task groups completed the performance goals tables for buildings and infrastructure systems, the results could be put into summary matrices [slide 20] as previously discussed. This table gives an 
overview of the infrastructure performance overall. Looking at this and the performance goals tables for the buildings and infrastructure systems provide a lot of information. By looking at the table, it is evident that the buildings have a large resilience gap, which is a concern. Although the gap in transportation is small, recall that the lone bridge crossing the Central River is a high priority for Riverbend.

Step 4 of the process (Chapter 5 of the Guide) was to develop a plan. This was done using the gaps identified in step 3, and identifying solutions that could be used to close those gaps. There are a variety of types of solutions that can be used, including those for new construction, existing construction, long-term administrative, and short-term administrative. Continuing with the transportation example, the bridge was a concern because failure could cause disruptions to commuters and transport of goods as well as eliminate the source of clean water. The planning team worked with the transportation task group to identify two solutions: 1) Work with the State DOT to seek support for a second bridge crossing that will provide support for growth, eliminate current traffic congestion, and add redundancy to the system; 2) Replace the existing bridge with one at a higher elevation to mitigate the impact of floods.

Other solutions identified by the task groups included building a flood protection levee for the National Aircraft Parts factory; restoring wells in Riverbend that could be used for water in the case of emergency; initiating buy-back programs for residents and businesses in older buildings in the downtown area that are vulnerable to flood; developing an energy assurance plan; developing a seismic retrofit initiative for downtown businesses not vulnerable to flooding; and purchasing charging stations for cell phones that can be used after a hazard event.

Once all the solutions were identified, the planning team prioritized the solutions and developed a 50-year implementation strategy. The solutions were prioritized as follows: 1) Purchase charging stations within six months; 2) Initiate buy-back programs within two years since they would take approximately 30 years to complete; 3) Apply for a FEMA Pre-Disaster Mitigation program grant to build a levee within three years; 4) Restore the wells for water within three to five years; 5) Develop an energy assurance program within five to ten years; 6) Construct a new bridge within five to ten years; 7) Replace the existing bridge in approximately 15 years; 8) Initiate the seismic retrofit program within 10-15 years to be completed in approximately 30 years.

Once the plan was developed, Step 5 was to have the plan documented, reviewed, and approved. Riverbend's resilience plan included summaries of the reports from the task groups characterizing the social dimensions and built environment of the community, long-term goals, the hazards faced by the community, performance goals tables (including summary matrices), list of solutions, and the prioritization and schedule for implementation of those solutions. Riverbend held public meetings and a 60-day comment period to collect public comments. They then incorporated the comments as needed and finalized the plan.

Once the plan was approved, Riverbend began implementing their strategy. They initiated many of the longer-term solutions first so as to not cause delays in the future. The planning team also tracked their progress and posted it to the city's website so it was available to the public. The plan was reviewed annually and adjusted when needed. 
Community Resilience Workshop: Release of Draft Community Resilience Planning Guide for Public Comment Introduction to Community Resilience Planning Guide Volume II

\section{Introduction to Community Resilience Planning Guide Volume II}

The discussion of Volume II was split into two short panel sessions moderated by Mr. Cauffman. The first session contained presentations on the higher-level chapters of Volume II. These included presentations from the following:

- Dr. Liesel Ritchie, Natural Hazards Center at University of Colorado at Boulder - Chapter 9: Understanding and Characterizing the Social Community

- Dr. Kent Yu, SEFT Consulting Group - Chapter 10: Dependencies and Cascading Effects

- Mr. Robert Pekelnicky, Degenkolb Engineers - Chapter 11: Buildings

- Dr. Frank Lavelle, Applied Research Associates - Chapter 16: Metrics

Summary of Dr. Ritchie's Remarks

[The slides associated with the following text are located on the NIST.gov website.]

The built environment supports the social institutions of a community. As a result, the purpose of Chapter 9 (Understanding and Characterizing the Social Community) is to provide context and tools to guide a community's planning team in understanding and characterizing their social community. It is important for communities to understand how the social and economic dimensions drive the requirements of the built environment. Recall that Step 2 of the methodology discussed in Volume I is to understand the situation. This requires identifying the social drivers and how they interact with each other as well as the built environment. Communities should work to define their social institutions. This slide [slide 3] shows eight social institutions: Education, Health, Family, Government, Religious \& Cultural Beliefs, Media, Community Service Organizations (CSOs), and Economy.

In implementing the methodology presented in the Guide, it is important to identify and use a given community's social capital. This enables communities to work toward community goals, such as planning for resilience. Specifically, this helps communities to complete the first two steps of the methodology discussed in Volume I: 1) Form a Collaborative Planning Team; and 2) Understand the Situation.

As a part of Step 2, we need to keep in mind that not all people use community systems in the same way or even have access to them. Therefore, it is important to identify vulnerable populations and incorporate the perspectives and needs of these populations in the planning process. Vulnerable populations may include the elderly, young children, people living in poverty, those who are disabled, people with chronic physical or mental illnesses, or minority groups. Furthermore, consideration should be given to groups of people who are not considered vulnerable populations, but could become vulnerable in a disaster such as students, renters, single-parent families, historic neighborhoods, and small businesses.

Identifying the links between the social institutions and built environment is critical to complete Step 2 of the methodology provided in Volume I. Some social institutions rely on the built environment more heavily than others. The chapter provides tables that show examples of how the social institutions rely on the built environment. These tables are one way that communities can summarize and document the links between the social and built environments in the process of planning for resilience.

Summary of Dr. Yu's Remarks

[The slides associated with the following text are located on the NIST.gov website.]

The dependencies between buildings and infrastructure systems can cause unforeseen disruptions if not accounted for in long-term planning. Both internal and external dependencies are important to consider. To illustrate this issue, one can look at what happened during the Northeastern blackout in 2003. First, an electricity generating plant went offline during a high-demand period. This resulted in high strain being put on nearby high-voltage power lines. Several power lines then came in contact with trees, which tripped relays. Unfortunately, there was also a control room software bug that resulted in delayed alarms 
Community Resilience Workshop: Release of Draft Community Resilience Planning Guide for Public Comment Introduction to Community Resilience Planning Guide Volume II

and, thus, response by operators for over one hour. Transmission lines became overloaded when load was transferred to them, which caused relays to trip. The transmission grid disruption led to over 200 power plants being forced to shut down, ultimately causing a blackout that affected approximately 50 million people in the Northeast U.S. and Canada. This process illustrates the impact of internal dependencies within an infrastructure system.

These failures can cascade into other infrastructure systems (i.e., external dependencies). Again, using the 2003 Northeast blackout as an example, the loss of electric power led to disruptions in other systems:

- Hundreds of people were trapped in elevators

- All trains into and out of New York City were shut down

- Fuel could not be pumped at gas stations

- Batteries and generators were exhausted causing cell site failures

- Television networks could not be broadcasted as usual

- Water pumps were not functional causing a loss of system pressure and a boil water notice In the Guide, we consider four dimensions of dependencies: 1) Internal and External; 2) Time; 3) Space; and 4) Source.

As illustrated by the Northeast blackout example, internal dependencies include dependencies on physical infrastructure, equipment and supply availability/performance, and operations centers within the same system. External dependencies are important to consider so one can understand what other infrastructure systems a given system relies on to function and which other systems may depend on that system.

The performance goals discussed throughout the Guide are a function of time. Recall that there are short-, intermediate-, and long-term phases. Dependencies may change from one recovery phase to another.

The space dimension should be considered because many infrastructure systems are co-located with other systems, particularly with transportation corridors. The space dimension also impacts the location from which a community may be able to receive assistance in recovery. For local events such as a tornado or tsunami, the impacted communities may receive aid from neighboring communities. However, for widespread events, such as earthquakes or hurricanes, support from further away may be necessary.

The source dimension should be considered because many infrastructure systems include large networks to deliver resources to a key supply or distribution node. In the Pacific Northwest, for example, Oregon's Liquid Fuel Tank Farm relies on refineries in Washington State for supply of liquid fuel.

Summary of Mr. Pekelnicky's Remarks

[The slides associated with the following text are located on the NIST.gov website.]

Historically, we have designed buildings for life safety, not functionality or resilience. As a result, after many hazard events, many buildings are safe but cannot serve their function to the community. In both Volumes I and II, we classify building performance for buildings into four categories: A) Safe \& Operational; B) Safe \& Usable During Repair; C) Safe \& not Usable; and D) Unsafe. For buildings that are critical to a community, the goal would be for these buildings to be safe and usable (category A). For some buildings, it may be reasonable to be operational while some repairs of light damage take place (category B). Life-safety only may be appropriate for many buildings since not everything can be operational immediately after a hazard event. Category D, Unsafe, is what we want to avoid. Though we may not be able to reach these goals with every building, by categorizing buildings into clusters, we can strive for restoring functionality of the building cluster as a whole in a community, which is more feasible.

Improving our design and construction methods is a good first step towards creating a more resilient building stock in the long-term future because buildings are replaced over time. For new building design and construction, current standards do not address functionality for every hazard. For example, seismic 
design considers life safety whereas wind design focuses on keeping the building envelope in place, which can keep the building operational. Some hazards, such as tsunamis and tornadoes, do not have standards at all yet. Furthermore, requirements of architectural, structural, and mechanical codes/standards are not always aligned.

Codes and standards are continually evolving. However, structural standards are not typically retroactive. Some owners do invest in upgrades to meet the current standards when they have opportunities to do so. However, retrofits are often expensive and disruptive to occupants.

\section{Summary of Dr. Lavelle's Remarks}

[The slides associated with the following text are located on the NIST.gov website.]

Community resilience metrics are needed for communities to understand their current situation, assess their planning options and strategies, and to make informed decisions based on scientific information. Furthermore, metrics could be used to monitor the progress of a community in its efforts to reach their specific goals.

Metrics can also be used to assess the anticipated benefits of changes made to the built environment when planning for resilience. For example, metrics could be used to assess benefits of siting, designing, and constructing individual buildings or infrastructure system components. Benefits could also be assessed for repair and restoration projects, or operational and maintenance purposes.

Currently, there are four general types of community level metrics that focus on: 1) Recovery times; 2) Economic vitality; 3) Social well-being; and 4) Ecological footprint. There are many different options for metrics that exist, several of which are discussed in Section 16.3 of the Guide. Many methodologies for combining metrics and assessing community resilience have also been proposed in the literature. Several examples of these are discussed in Section 16.4 of the Guide.

Some of the methodologies discussed in the Guide include:

- San Francisco Planning and Urban Research Association (SPUR) framework

- Oregon Resilience Plan

- United Nations International Strategy for Disaster Risk Reduction (UNISDR) Disaster Resilience Scorecard

- Community \& Regional Resilience Institute (CARRI) Community Resilience System

- Communities Advancing Resilience Toolkit

- Baseline Resilience Indicators for Communities (BRIC)

- Rockefeller City Resilience Framework

- National Oceanic and Atmospheric Administration (NOAA) Coastal Resilience Index

- Federal Emergency Management Agency (FEMA) HAZUS methodology

There is no "correct solution." Each methodology has its own strengths that may be better suited for a given community.

The Guide focuses on recovery times as a metric. These performance goal recovery times can be developed through a range of processes, from using expert judgment to detailed modeling of systems. The process used to determine the performance goals is likely to be influenced by the cost. 
Community Resilience Workshop: Release of Draft Community Resilience Planning Guide for Public Comment Introduction to Community Resilience Planning Guide Volume II

Once the first panel completed its discussion, the next panel of presenters for Volume II began its discussion. This panel discussion focused on the chapters detailing the individual infrastructure systems. These included presentations from:

- Mr. Theodore Zoli, HNTB Corporation - Chapter 12: Transportation Systems

- Mr. Erich Gunther, EnerNex - Chapter 13: Energy Systems

- Mr. David Mizzen, Applied Research Associates - Chapter 14: Communication Systems

- Mr. Donald Ballantyne, Ballantyne Consulting - Chapter 15: Water and Wastewater Systems

Summary of Mr. Zoli's Remarks

[The slides associated with the following text are located on the NIST.gov website.]

Transportation systems are critical to the societal needs of the community. Transportation is needed in disaster response and recovery to enable restoration of infrastructure systems as well as to allow access to critical facilities. The transportation network is very complex since it consists of multiple systems, many of which interconnect: roads and bridges, rail, airports, ports and harbors, waterways, and pipelines. In fact, people and goods are often moved by multiple transportation systems, particularly in larger cities. The performance of the transportation system during and after a hazard event will have a direct impact on the resilience of a community and its other infrastructure systems.

Transportation is needed both during daily life and after disasters to support the eight social institutions discussed earlier (family, economic, government, health, education, CSOs, religious organizations, and media). Many of the needs of the community remain the same in both daily life and after disasters. For example, to support the social institution of family, transportation is needed to enable people to get to the homes (buildings) in which they live.

It is important to determine the hazards that your community faces and how that could impact your transportation systems [slide 5]. Communities can look at their past performance and evaluate where improved performance is most needed. For example, after Hurricane Katrina struck the New Orleans area, many components of the transportation network were inoperable for weeks, including bridges, rail, pipelines, ports, and airports [slide 6]. We were, however, able to make adjustments and use bridges that were intended to carry only eastbound traffic for both eastbound and westbound traffic.

Communities should work with key stakeholders to set performance goals for routine, expected, and extreme events. For transportation, it is important to prioritize the systems that are critical to ingress, egress, and critical facilities. Then, the desired restoration times of systems to support community recovery can be determined.

\section{Summary of Mr. Gunther's Remarks}

[The slides associated with the following text are located on the NIST.gov website.]

The potential for cascading effects is significant with loss of energy because all infrastructure systems rely on power in one way or another. Starting off with an example of restoration times for electric power, we can consider the Northridge earthquake and shakeout scenario. The Northridge earthquake, which registered as a 6.7 on the Richter scale and caused approximately $\$ 20$ billion in losses, damaged about $25 \%$ of power lines in the Greater Los Angeles area. It took 14 days to restore electric power to the normal level of service. For a worst case shakeout scenario, the Los Angeles area conducted a study to determine what would occur if a 7.8 magnitude earthquake occurred in the region. It was estimated that about $13 \%$ of the system would be damaged, and it would take over 28 days to restore power to the normal level.

In preparing for the next hazard event, three key prioritization issues are electric energy, non-electric energy (liquid and gaseous fuels), and communications. When considering electric energy infrastructure, 
Community Resilience Workshop: Release of Draft Community Resilience Planning Guide for Public Comment Introduction to Community Resilience Planning Guide Volume II

there are several challenges, such as underground infrastructure (transformers and ducts), substations with high- and low-voltage feeds, fuses instead of breakers in many locations, and a lack of automation. For all of these systems, we need to identify their dependencies to anticipate how they will perform during a hazard event. Diesel back-up generation is also very important in the aftermath of disaster events. Power infrastructure is becoming more dependent on communications, particularly when disruptions occur, so that distribution can be sectionalized and outages can be limited as much as possible.

There are also several key recovery issues to consider when planning for resilience. Bulk generation may not always be the highest priority. Distributed generation can actually be helpful in recovery since it is not all going to be impacted. Coming up with work-arounds for transmission of electric energy can be helpful in the short-term, while hardening key corridors can be done in the longer-term. Distribution is often a very high priority to deliver service to the customers. It is important to prioritize critical services in a community and activate mutual aid agreements, if necessary. Furthermore, communities can work with their stakeholders to identify where temporary solutions to provide power are needed, such as for gas stations and grocery stores. Recall that after Hurricane Sandy, many gas stations had plenty of liquid fuel, but they could not pump it out of the ground because electric power was not functional.

When prioritizing the recovery levels of power for facilities within the community, different levels of recovery will be needed for emergency facilities, critical rights-of-way that support restoration of other infrastructure systems, and restoration that supports community recovery. This can be done through energy assurance planning. California Local Energy Assurance Planning (CaLEAP) has developed a process to implement an Energy Assurance Planning process [slide 6]. You will notice that this process is similar to the methodology discussed in Volume I of the Guide.

Summary of Mr. Mizzen's Remarks

[The slides associated with the following text are located on the NIST.gov website.]

There are three key concepts discussed throughout the communications chapter. The first concept is that communities and service providers should work together to prioritize needs, as discussed in Chapter 9 of the Guide. The second concept is that communication systems depend on other infrastructure systems, such as electric power, which again shows the importance of dependencies as discussed in Chapter 10 of the Guide. Finally, the third point is that there are already many potential solutions to problems that can be used to close resilience gaps. This is because service providers work in a competitive business environment and are continually working to adapt to evolving technology as well as increased consumer demand and expectations.

It is important for communities and service providers to work together to identify priorities for service before an event, not after. Emergency 9-1-1 service is critical in all communities, but other prioritization of services may vary, such as for a specific hospital. Furthermore, the need for the type of service (oneway vs. two-way communication) should be considered.

Dependencies on other systems also should be considered. Access, fuel, and security are the three things that service providers often say they need following a hazard event. Transportation is needed for repair crews to access sites, and electric power is needed for communication systems to function. There is also a big focus in the communications industry on liquid fuel to supply standby power. There are many considerations for standby power, such as placement of generators, use of permanent vs. temporary generators, and alternative sources of power. Permanent generators can be expensive and require periodic maintenance and testing to ensure they will function when needed. On the other hand, temporary generators can have challenges associated with them such as the inability to access sites after a hazard event, deploying a large number of generators requires sufficient staffing, and refueling can be difficult after a hazard because fuel may not be available.

Communities should work with their service providers and other stakeholders to identify solutions to 
Community Resilience Workshop: Release of Draft Community Resilience Planning Guide for Public Comment Introduction to Community Resilience Planning Guide Volume II

close resilience gaps. Both construction and administrative solutions can be used to make communication systems more resilient. Solutions include hardening communications buildings (e.g., Central Offices, Internet Exchange Points, etc.), eliminating single points of failure in the distribution network where possible, and using multiple methods of communication. For example, one-way communication systems (cable and broadcast) can be used to inform the public if critical services, such as 9-1-1, are unavailable due to failure of the landline, and provide alternative means of contacting emergency services using cell phones. Temporary solutions, such as Cell on Light Trucks (COLTs), can also be used. However, we want to encourage longer term solutions and COLTs are limited resources that are expensive.

Critical facilities should be made aware of multiple administrative solutions that are useful to prioritize their calls in a disaster event. The Government Emergency Telecommunications Service (GETS) and Wireless Priority Service (WPS) programs prioritize landline and cell service, respectively, for customers supporting national security and emergency preparedness/response after disaster events. The main goal of these programs is to give priority service, but if significant infrastructure damage is incurred, these services may not be available. Therefore, it is important to maintain the integrity of the infrastructure. The Telecommunications Service Priority (TSP) is another option that prioritizes participants when they need additional lines or service restoration at any time, not just after a disaster event.

\section{Summary of Mr. Ballantyne's Remarks}

[The slides associated with the following text are located on the NIST.gov website.]

Water is important for many reasons. Drinking water for people is an obvious need. Furthermore, it is needed for daily functions such as waste disposal and washing/maintenance. Hospitals need water for cooling (e.g., HVAC systems) and laundry. It is also important for other infrastructure systems, such as for cooling systems of communications equipment and computers. Water is critical for fire suppression, including buildings with sprinklers not just for firefighters' hoses. Commercial and industrial buildings also rely on water for a number of uses. Restaurants use water for food preparation and cleanliness. Hotels need water for laundry and cleaning as well. Manufacturing processes and cooling systems for industrial machinery also rely on water. Water systems are vulnerable to a number of hazards. Slide 2 shows a water tank that failed during Hurricane Katrina. Earthquakes can also cause pipes to fail, buckling of tanks, etc.

Water and wastewater systems have dependencies with many other infrastructure systems. Electric power is needed for pumping in water and wastewater systems as well as to operate treatment plants.

Transportation is needed for emergency repair crews to access sites where damage to the system has occurred. Moreover, to isolate a failure in a distribution system, workers need to be able to access numerous valves so that the system can continue to operate. Communication is also needed to enable emergency repair crews to work effectively and efficiently. Furthermore, water systems rely on Supervisory Control and Data Acquisition (SCADA) systems to control and monitor its functionality. Loss of this system creates a lot of operational and recovery challenges after a hazard event. Access to a chemical supply is also important to ensure that water is being treated properly. Therefore, if there is a failure or disruption between the source and the water treatment plant, it impacts the water utility.

Recovery time can be impacted by a number of factors and, thus, a number of issues need to be taken into consideration. Prioritization of needs is necessary to enable critical functions in a community. This helps leaders make decisions regarding where to deploy their resources (e.g., workers, backhoes) and how to manage mutual aid contracts. Recovery time also depends on the extent of damage to the system, the level of redundancy in the network, preparedness for a disaster, and availability of resources. The number of staff and equipment available to complete repairs to the system has a significant influence on how quickly service can be restored. Furthermore, having a stock of supplies can speed-up the repair process. If new pipes have to be transported into the community, the recovery time will likely take longer. 
Community Resilience Workshop: Release of Draft Community Resilience Planning Guide for Public Comment Panel Session: Implementation of Community Resilience Planning Guide

\section{Panel Session: Implementation of Community Resilience Planning Guide}

Mr. Cauffman moderated a panel session in which the following guest speakers discussed past events and the resilience planning their communities are undertaking:

- Mr. John 'Rusty’ Russell, Emergency Management Agency Director, Huntsville, Alabama

- Ms. Courtney Barker, City Manager, Satellite Beach, Florida

- Mr. Gregory Guibert, Chief Resilience Officer, Boulder, Colorado

- Mr. Anthony Rosano, Resiliency Coordinator, Office of Emergency Management, Howard County, Maryland

Summary of Mr. Russell's Remarks

[The slides associated with the following text are located on the NIST.gov website.]

Huntsville, Alabama is located in Madison County and is a diverse area with a strong technological and space industry. The average household income, as a result, is quite high.

There are a number of large employers in Huntsville, including Polaris, Toyota, Boeing, Raytheon, SAIC, Northrop Grumman, Lockheed Martin, Intergraph, Chrysler, and the City of Huntsville. The area is growing and agricultural land is now being converted to residential use in many areas. Huntsville has nine water systems, six wastewater utilities, and eight electrical transmission feeds. It is home to the US Space and Rocket Center, three school systems, six colleges and universities, and a sprawling downtown area.

As previously discussed, today marks the fourth anniversary of the tornado outbreak that impacted several states in the southeastern United States, including Alabama. Prior to this event, April 3, 1974 was the standard for emergency managers dealing with disasters. That outbreak had 148 tornadoes across 13 states, resulting in 301 deaths. The April 27, 2011 event had 226 tornadoes across four states in the Southeast, causing 313 deaths. In Alabama alone, there were 71 confirmed tornadoes resulting in 248 deaths. We also had 35 tornadoes a couple of weeks prior to this outbreak on April $15^{\text {th }}$.

April 2011 set the record for how many tornadoes there were in one month -875 reported tornadoes. Prior to that, the record was 542, which occurred in May 2003. In April specifically, the previous record for number of tornadoes was 267, while the average number of tornadoes in April is 161 (about 5.5 times less than April 2011).

There were about five days warning from the National Weather Service (NWS) ahead of April $27^{\text {th }}$ that a significant outbreak was possible. The community was aware and prepared for severe weather. However, this type of outbreak had not been experienced before.

On April 27, 2011, tornado warnings started between 3 and 4 a.m., and over the remainder of the day 92 tornado warnings were issued by the Huntsville NWS, which covered 13 counties. Madison County alone experienced 28 tornado warnings that day. A lot of the local media and the NWS were tracking multiple storms at one time. For example, this radar picture shows four tornadoes on the ground [slide 8].

We had many people representing many entities from the county (police, fire, schools, etc.) at the Emergency Operations Center involved in monitoring the situation because everybody understood the potential danger of the storms. Live updates and radar were shown on cable television [slide 10]. However, each time a new warning was issued, it automatically blocked out 47 seconds of potentially life-saving information since other storms were occurring simultaneously. We are now working with our cable companies to make sure these automatic block outs of information do not occur.

There were 92 tornado warnings issued on April $27^{\text {th }}$ in the Huntsville area. There were 67 tornado warnings in all of 2010. Recall that tornado warnings are issued for polygons, so when the storm moves beyond the polygon, a warning is issued for the next polygon, which created an incredibly high number of warnings in this case [see slide 12]. The actual tracks and their EF-scale ratings are shown here [slide 13]. Approximately two-thirds of Alabama was impacted by tornadoes and severe weather over 18 hours, with 
Community Resilience Workshop: Release of Draft Community Resilience Planning Guide for Public Comment Panel Session: Implementation of Community Resilience Planning Guide

up to four storm tracks that overlapped. At the end of the storms in Alabama, 248 were killed and 13,000 buildings were heavily damaged or destroyed. The American Red Cross found in their statewide assessment that 6,237 single-family homes were destroyed, 5,039 homes were heavily damaged, including 1,890 mobile homes, and the most heavily impacted areas were Tuscaloosa and Birmingham. Many buildings were damaged [slide 15] and two miles of 500kV transmission lines were destroyed by the storms [slide 16], leaving us without power for five to seven days in northern Alabama. As a result generators were brought in to keep water and other infrastructure systems functioning.

There were many lessons learned during the event. We provided up-to-date public information and worked with County Commissioners and Mayors to provide mutual aid, which helped gain the trust of the people. Backup generators at cell towers ran out of fuel because they were not accessible due to surrounding debris, which caused unreliable cell phone coverage, hundreds of thousands of dollars of food spoiled due to extended loss of power, gas stations that had power had long lines, and a curfew was put in place during power outages to mitigate looting and violence. Radio stations removed regular programming and used call-in information sharing from community members to allow people in the community to help each other.

As a result of the physical damage, many services were not available. For example, some internet providers were offline for several days, VOIP systems were not functional, and businesses were closed so employees could not work, revenue and income were lost, schools and daycare centers were closed, bank accounts could not be accessed, and credit cards could not be used. However, major retailers such as WalMart, Costco, Sam's, and Target were open three days after the storms, which helped in recovering significantly. Other challenges in recovering from the tornadoes included local utilities having to wait for transmissions lines before they would begin restoration in their localities, and removal of millions of cubic yards of debris.

After this event, Huntsville has made a conscious effort to become more resilient. We established a longterm recovery committee, first responders reviewed and updated their plans to reflect the lessons learned from the event, and many critical facilities and private sector businesses have focused on becoming prepared for prolonged power outages. Hundreds of residents have also installed safe rooms, and community storm shelters have been added where possible.

The Mayor of Huntsville initiated a program called "Exemplar City" to support community-wide operations. This program includes three components: 1) Blueprint for Safety; 2) Blueprint for

Sustainability; and 3) Blueprint for Security. Blueprint for Safety focuses on providing emergency responders with emerging technologies and conducting real-time imagery to help with situational awareness. Blueprint for Sustainability aids in long-term planning to develop energy assurance. Blueprint for Security focuses on enhancing cyber-security for the community to help employers and the city.

\section{Summary of Ms. Barker's Remarks}

Satellite Beach (Figure 2) is located on the Atlantic side of Florida, south of Cape Canaveral. The population is about 10,000 people and it is located on a barrier island. Satellite Beach is primarily a residential community. There is a lot of intellectual capital in Satellite beach, including CEOs of several companies in Brevard County and professors from the Florida Institute of Technology. In fact, one of those professors is a vocal advocate for resilience and spearheaded a Sea Level Rise Study approximately five years ago. 


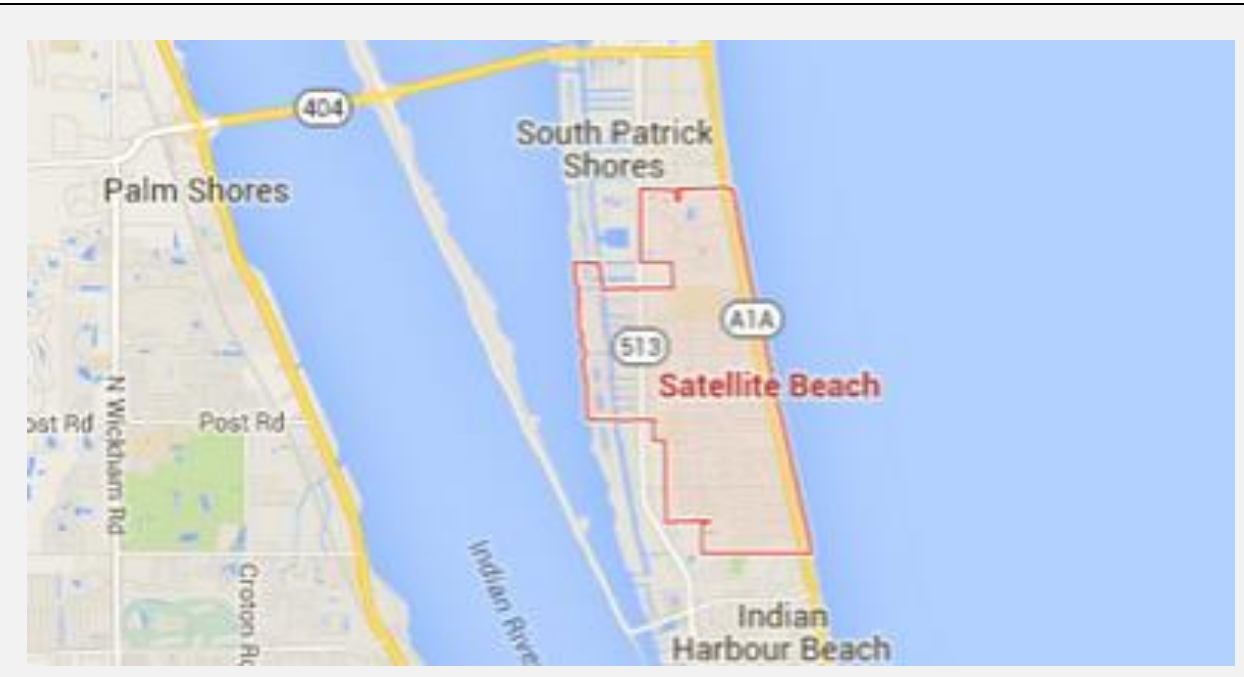

Figure 2. Google Maps View of Satellite Beach, Florida

The main concerns in Satellite Beach are flooding and erosion. In the 2004 hurricane season, we lost about half of the infrastructure (including part of the road) near the beach. We were about to begin a project to rebuild this area, but realized that we needed to make sure we were planning carefully because storms are more intense now and flooding can be very disruptive, particularly on a barrier island. For example, in a large community such as Houston, flooding of one intersection will cause drivers to go to another intersection to get around it. However, on a narrow barrier island where there is no alternative route, flooding of an intersection becomes a real problem.

We wrote a grant with the East Central Florida Planning Council and purchased a survey tool to engage our community to determine how the community wanted us to improve the infrastructure (e.g., beach erosion, flooding, storm-water drainage improvements, etc.). We found that the residents of Satellite Beach are very supportive of resilience and have used some of their ideas to move forward in drafting policies. We have now applied for another grant from the Florida Sea Grant to assess our infrastructure for risk management purposes.

Since this is an ongoing process now, our biggest challenge is from a management perspective. That is, since we have many new projects continuing to start-up, we need to be able to manage and oversee the projects so that we are successful in becoming more resilient.

Summary of Mr. Guibert's Remarks

[The slides associated with the following text are located on the NIST.gov website.]

Boulder, Colorado is a prosperous small town with a population of about 100,000 . Boulder has a diverse economy with a highly educated workforce, and includes two universities, federal research centers, technological start-ups, and a strong agricultural sector. It is consistently rated one of the best places in the country to live, work, and play. Boulder is also well known internationally for its progressive land use planning, preservation of open space, and dual use for greenways and floodways. It is situated in an arid climate with a steep elevation gradient to the west.

As part of the Rockefeller 100 Resilient Cities Program, we broke out shocks and stresses, and then linked them to one another. In Boulder, we determined our high risks (i.e., shocks) to be drought, flood, pandemic flu, wildfire, and winter storms, while our medium risks include dam failure, extreme temperatures, infrastructure/building failure, and hazardous materials accidents. We identified our top stresses as environmental degradation, transportation options, energy affordability/continuity, economic diversity, and housing affordability. So, you can see that most of our natural hazard risks are linked to 
Community Resilience Workshop: Release of Draft Community Resilience Planning Guide for Public Comment Panel Session: Implementation of Community Resilience Planning Guide

climate or climate change. We engaged technical experts and members of the community through a series of workshops to link the shocks to the stresses [slide 4].

The 2013 flood occurred after the wildfires in 2010 and 2011 that changed our landscape significantly. We then received close to the annual average of rain (18 inches) in eight days. This was determined to be a 1000-year rainfall event, but only a 100-year flood event. It was not the level of flood for which we had previously planned. The flooding resulted in access to mountain communities being cut-off along six of seven canyons, caused $\$ 300$ million in private property damage, and \$27 million in municipal property damage. However, only $\$ 14$ million of the damage was reimbursable, so the losses were huge.

There were a number of lessons learned as a result of the flood. For example, although green infrastructure is important and FEMA provides credits in their rating system for making improvements to green infrastructure, these types of reconstruction projects are not reimbursable. Ground water intrusion was an unforeseen issue that we are still encountering today. Transportation fragility is impacted by the open space boundary. Furthermore, transportation impacts mutual aid and trauma care. There is a need for flexible municipal staffing and financial mechanisms. Local governments reinforcing the core principals of know your neighbor, have a plan, and know your risk to its residents is important so things go as smoothly as possible if a disaster event does take place. Another concern is that even though the public can become very focused on how to make improvements immediately after a disaster takes place, they can become burned out and return to their ways from before the event.

Boulder has been using progressive land use planning and floodplain management for over 30 years. We are now expanding these concepts to include additional social and economic dimensions. We are also incorporating resilience concepts into the next update of the Boulder Valley Comprehensive Plan and Human Services Master Plan.

As discussed earlier, we are developing a resilience strategy as part of the Rockefeller Foundation's 100 Resilience Cities Global Campaign [slide 8], which can be looked at from many perspectives [see slides 10-16]. There are four major dimensions, including Infrastructure and Environment, which is how most of the topics discussed today would be categorized.

The Rockefeller Foundation process and the Guide discussed today have a lot of commonalities. The Rockefeller Foundation process has two phases. The first phase (first four to six months) focuses on evaluating the existing state of resilience and understanding where gaps exist. The second phase is a thorough analysis of the community, followed by developing a resilience strategy to be implemented.

Stakeholder engagement is crucial for communities to be successful in addressing resilience. For the 100 Resilient Cities Program, we have mapped the stakeholders to different categories [slide 17], which will vary by community. There are several different roles in the effort to become resilient using the Rockefeller Foundation approach. The Chief Resilience Officer (CRO) is the overall project director responsible for delivering the city's resilience strategy. This CRO is often supported by a working team for day-to-day activities. A Resilience Steering Committee provides advisory, decision-making, or other roles as defined by the City Team. Working groups also support the CRO's activities. Strategy Partners (e.g., consultants) support the CRO in project management, and provide technical expertise and other guidance. The 100 Resilience Cities Relationship Manager also provides support to the CRO using his or her available resources.

Many of the participating cities around the globe have differing organizational structures, such as those in Berkeley (California), Rio De Janeiro (Brazil), Byblos (Lebanon), and Vejle (Denmark) [see slides 1922]. However, the goal of becoming more resilient remains the same for each of these communities. 
Community Resilience Workshop: Release of Draft Community Resilience Planning Guide for Public Comment Panel Session: Implementation of Community Resilience Planning Guide

\section{Summary of Mr. Rosano's Remarks}

Howard County, MD began a resilience program about two years ago. Howard County is situated between Washington D.C. and Baltimore. Howard County does not contain any municipalities, unlike most of the counties in Maryland. We have a number of strategic partners in our county, including the National Security Agency (NSA), Fort Meade, Johns Hopkins University Applied Physics Laboratory, Howard County Historical Society, and Johns Hopkins Howard County General Hospital. Columbia would be the second largest city in Maryland if it was incorporated.

We use an all-hazards approach in our risk assessment and planning, including 14 natural hazards and 12 human-caused. In 2011, Tropical Storm Lee caused about five to six feet of flooding in Ellicott City, a historic district in Howard County. We have mitigated our flood hazard by building a channel that runs by the buildings in Ellicott City, and it has proven to be effective.

Hurricane Agnes in 1972 caused approximately 14.5 feet of flooding in Howard County [slide 7]. In 1975, Ellicott City experienced 9.5 feet of flooding.

Although natural hazards have been the main point of discussion today, human-caused hazards, such as the January 25, 2014 shooting at a mall in Columbia, MD, have a large economic impact on the community. This event had as much of an economic impact on our county as any of our natural hazards. It caused a lot of cascading effects in terms of the social environment because (for example) people were concerned about taking their children to school. As a result, we have also started to apply resilience concepts into our emergency response. Our police and fire departments are creating new ways to respond to shooting events more efficiently.

Another example is the Ellicott City train derailment. The derailment was near historic buildings and caused delays to other trains transporting goods nationally. Fortunately, the train only had coal on it, but if it had contained other materials the situation could have been much worse. The train fell onto cars in a parking lot, which was extremely close to historic buildings [see top left photo on slide 11].

The Howard County Resilience Program is defined as critical infrastructure protection in conjunction with governmental continuity planning. We have an organization chart with a County Executive and Chief Administrative Officer, who oversees the emergency management, police, and fire departments. Our Resiliency Working Group is composed of Directors, Deputy Directors, and other decision-makers. Many members and departments, including police and fire, also support the resiliency program. We also coordinate with external parties, including the Regional Transit Authority, Maryland Emergency Management Agency (MEMA), Department of Defense (DOD), and our Historic Society. We are including key stakeholders, such as the Economic Development Association, and critical infrastructure owners and operators.

Fifteen of the sixteen Department of Homeland Security (DHS) Infrastructure Sectors are represented in Howard County. We have a risk assessment program that took place over two years and engaged experts to complete a county-wide assessment. The next step is to complete assessments that will be site-specific for critical infrastructure.

Our continuity program focuses on government, operations, critical systems continuity, and incorporating best practices of business continuity from the private sector. In terms of long-term resiliency planning, we are incorporating smart-growth initiatives into county planning and utilizing Geographic Information Systems (GIS). We are also incorporating Crime Prevention through Environmental Design (CPTED) principles into long-term planning for Howard County, and continuing outreach to residents, critical infrastructure owners and operators, businesses, the economic community, and the historic building preservation community. 


\section{How to Submit Public Comments}

All comments on the Draft Community Resilience Planning Guide for Public Comment are welcome. Please go to the NIST website (http://www.nist.gov/el/building materials/resilience/guide.cfm) to download Volumes I and II of the Guide. There is also a public comment form that should be filled out with your comments and emailed to resilience@nist.gov. These comments will be shared with the writing team and addressed. The comments received will be posted to the NIST website so that all of the comments can be seen by the public. 